\title{
Predicting Alcohol Consumption in Hospitality Populations Using Sense of Coherence
}

\author{
Carl P. Borchgrevink \\ Michigan State University, Michigan, USA
}

\begin{abstract}
This paper aims to introduce the claim that hospitality students and hospitality employees drink more alcohol than other students and employee groups and to explore and explain this alcohol consumption disparity using the sense of coherence (SOC) construct. Using a web-based questionnaire, college students were recruited, surveyed, and classified into hospitality and non-hospitality majors. Self-reported alcohol consumption, SOC, and a variety of demographic variables were measured. A total of 930 students participated of which $59.4 \%$ were female and $28 \%$ were hospitality majors. About $47 \%$ of hospitality students, $33 \%$ of other majors, $43 \%$ of women, and $38 \%$ of men were classified as at-risk consumers of alcohol. The overall SOC score was about 139 with a range of 69-191. None of the sub-populations differed significantly in SOC. While SOC does not predict major or occupational choice, SOC is a predictor of risky alcohol consumption.
\end{abstract}

Keywords: sense of coherence (SOC), alcohol consumption, addiction, hospitality industry and hospitality students, Alcohol Use Disorders Identification Test (AUDIT)

\section{Introduction}

Many propose that hospitality students and hospitality employees drink more alcohol than similar populations with alternate affiliations. The research to date has not been able to falsify this alcohol consumption hypothesis (Borchgrevink \& Borchgrevink, 2013; Kjærheim, Mykletun, \& Haldorsen, 1996; Larsen \& Jørgensen, 2003). If the proposition is correct, then an understanding of this disparity in alcohol consumption is needed to identify risk factors and possible predictors. This is important from two perspectives. Firstly, service quality, employee productivity and thus profits may suffer as a consequence of alcohol consumption among employees (Larsen, 1994; Frone, 2013). Secondly, this issue warrants attention as alcohol consumption is associated with a variety of health issues, and the health and well-being of hospitality business employees may unnecessarily suffer as a consequence.

Borchgrevink, Sciarini, and Borchgrevink (2010) suggested that fruitful explanations for the disparity in alcohol consumption may be found at the interpersonal and organizational levels. The most frequent etiology offered at the interpersonal level is the self-selection hypothesis. That is, it is believed that individuals do not choose a vocation or occupation at random. Rather, vocational and occupational choices are influenced by individual dispositions and personalities in such a manner that individuals seek work that meets their needs and drives. Thus, individuals with a predilection to drink will seek work where drink plays a major role.

Carl P. Borchgrevink, Ph.D., Associate Professor, The School of Hospitality Business, Michigan State University. Email: carlb@msu.edu. 
Discussions of the self-selection hypothesis can be found in the work of Plant (1979), Whitehead and Simpkins (1983), Kjærheim, Mykletun, and Haldorsen (1996), Zhu, Tews, Stafford, and George (2011), and Borchgrevink and Borchgrevink (2013).

A second etiology is that of organizational structure and intra-organizational social modeling. From this perspective, employees of hospitality businesses do not start their employment with a predisposition towards alcohol consumption. Rather, aspects of the work environment, including organizational policies and collegial pressures, shape employees into individuals that consume alcohol at levels higher than they would otherwise consume. This approach can be seen in the work of Whitehead and Simpkins (1983), Kjærheim, Mykletun, Aasland, Haldorsen, and Andersen (1995), and Corsun and Young (1998).

A third approach integrates elements of both perspectives above, as it contains both self-selection and shaping elements. In this case, however, shaping takes place through reference group and social network influences and is not restricted to the inter-organizational domain. In other words, potential hospitality business employees are influenced by their social networks and their relevant positive and negative reference groups. This socio-normative influence is generally conceived of as extra-organizational. The influenced individual may subsequently or concurrently self-select into occupations in which the adopted behavior is normative for the employees. While not adapted to employment situations, the potential influences of positive and negative reference groups are discussed by Klineberg (1954) and Newcomb (1958). Consistent with the referent other perspective, Robinson, Tobias, Shaw, Freeman, and Higgs (2011) demonstrated that the desire for social acceptance within dyads is associated with matched intradyadic food consumption. The impact of reference groups, affiliation needs, and social networks on alcohol consumption are discussed by O’Hara, Harker, Raciti, and Harker (2007) and Homish and Leonard (2008), respectively. In sum, the three etiologies above are consistent with Skog's (1985) finding that alcohol consumption levels vary on the basis of the culture and social network in which individuals are embedded, and the argument that alcohol consumption has a "pluralistic anchorage... and a multiplicity of causes" (p. 93). This study will attempt an explanation from the perspective of the self-selection hypothesis using Antonovsky's (1987; 1990; 1993) theory of salutogenesis and his sense of coherence (SOC) construct as explanatory vehicle.

\section{Literature Review}

\section{Alcohol Consumption}

There is some support for the claim that hospitality business students and hospitality business employees consume alcohol at higher levels than students and employees from other populations (Kjærheim, Mykletun, Aasland, Haldorsen, \& Andersen, 1995; Kjærheim, Mykletun, \& Haldorsen, 1996; Larsen, 1994; Kouvonen \& Lintonen, 2002; Larsen \& Jørgensen, 2003; Pizam, 2010). More recently, Borchgrevink et al. (2010) considered this claim using students attending a large mid-western university as sample and found moderate support. Subsequently, Borchgrevink and Borchgrevink (2013) explored whether the personality typologies could be used to explain self-selection into hospitality. While they found some support, overall they failed to predict student major using personality types.

\section{Salutogenesis and the SOC}

Aaron Antonovsky was a medical sociologist who became very curious as to why some individuals maintained their health while others' health deteriorated when facing similar health-debilitating circumstances. 
His intrigue started with the unexpected finding in 1970 that a higher percentage than expected (29\%) of women that survived the concentration camps of World War II and subsequent displacement and turmoil experienced emotional and physical health as good as $51 \%$ of the control group (Antonovsky, 1987).

In considering this counter-intuitive finding, he started to explore how these women differed from those women that had not maintained their health as well. He moved away from the prevailing pathogenic approach to health with a focus on the symptoms of the unhealthy and the established healthy-unhealthy dichotomy, and moved towards a consideration of health as a continuum rather than a static condition. He proposed a salutogenic theory that uses a health-illness continuum and seeks to explain how individuals move toward the health end of the continuum (Antonovsky, 1987; 1990). He suggested that movement towards health rather than illness could be explained by individuals' global disposition to the world, and put forth the SOC construct as primary explanatory vehicle (Antonovsky, 1979; 1987). In sum, he proposed that individuals that sensed that the world was coherent were relatively healthier than those who perceived the world as incoherent. The SOC has received much attention and is generally considered a psychometrically sound measurement model (Antonovsky, 1993; Geyer, 1997; Eriksson \& Lindström, 2005).

The SOC measurement model has a cognitive, a behavioral, and a motivational component, respectively labeled as comprehensibility, manageability, and meaningfulness. The measurement model taps: (1) the degree to which people understand what happens to them and to those around them; (2) the degree to which they believe that they can manage, personally or through their social network, the situation in which they find themselves; and (3) the degree to which they see and find meaning in their situation and world. While the SOC sub-scales have been considered as distinct constructs, Antonovsky (1993) suggested that item-development for the SOC scale was done for the scale as a whole and that it should be used as such. He also suggested that an individual's SOC stabilizes by the end of young adulthood, with subsequent fluctuations only occurring when the individual's pattern of life experience changes drastically.

Eriksson and Lindström (2006) reported that across 25 years the SOC construct has generally been associated with perceived health, and can explain and predict health. A few studies have investigated the SOC and alcohol consumption in non-college age populations (Midanik, Soghikian, Ransom, \& Polen, 1992; Neuner, Miller, Maulhardt, Weiss-Gerlach, Neumann, Lau, ..., \& Spies, 2006; Poppius, Virkkunen, Hakama, \& Tenkanen, 2008) and in this study, SOC will be used to attempt to explain the disparity of alcohol consumption within a student sample.

\section{Methods}

The Office for Survey Research (OSR) at a large mid-western university agreed to collect the needed data. The university registrar's generated random email lists of students to whom they sent a notice of a forthcoming study in which they were requested to participate. One week later, a link to the actual survey was included as well as notice of a choice of incentives for completion. The incentives included coupons for food items at local establishments. Approximately, two weeks after the initial mailing, a reminder was sent to the students. The OSR continued to solicit participants until the hospitality business sub-sample size was large enough to detect small effect sizes $(d=0.10)$ at the conventional power level of 0.80 (Cohen, 1988), that is, this study will be able to detect standardized mean differences of 0.10 but allows a 20\% risk of not finding significant $(p=0.05)$ differences when they actually exist. The students were given the researchers' contact information should they have questions but were provided confidentiality in that the OSR de-identified the data prior to providing the 
researchers with the raw data. The response rate among solicited students is $43.3 \%$. Prior to de-identification, the OSR tracked respondents by their university email address. Multiple entries were thus avoided.

\section{Results}

\section{Sample}

The sample consists of 331 (35.6\%) male students, 552 (59.4\%) female students, and 47 students who preferred not to disclose their gender, for a total sample of 930 students. The age of the respondents ranged from 18 years to 30 years $(\bar{x}=21.2, \mathrm{SD}=2.2)$ among the 887 who did report their age. Ninety-six percent $(n=890)$ disclosed their major and 262 students were hospitality business students while 628 reported a different major. The average reported semester credit hours are $13.3(\tilde{x}=14, \mathrm{SD}=3.0, n=896)$. Sixty-four percent $(64.1 \%, n=596)$ are gainfully employed and 30\% report working in hospitality businesses. About $6 \%$ (5.6\%) report working 40 or more hours per week, while 3.3\% work 30-39 hours, 16.8\% work 20-29 hours, 28.8\% work 10-19 hours, and 9.2\% work less than 10 hours per week. Sixty-four percent $(64.1 \%, n=596)$ of the sample is employed, of which $30 \%$ report working in hospitality businesses.

\section{Measurement Models}

Alcohol consumption. Alcohol consumption and associated risk levels were measured using the Alcohol Use Disorders Identification Test (AUDIT) (Babor, Higgins-Biddle, Saunders, \& Monteiro, 2001). This tool was developed by the World Health Organization to screen for excessive drinking and establish the relative population risk of harmful and hazardous drinking. The primary intent of AUDIT is to identify people who would benefit from a reduction in or abstention from alcohol consumption as the majority of excessive drinkers are undiagnosed (Babor et al., 2001).

AUDIT is recognized as a reliable and valid measure useful in diagnosing at-risk, harmful, and hazardous drinking among college students and non-college age populations that were not previously diagnosed as having problems related to alcohol consumption (Fleming, Barry, \& MacDonald, 1991; Saunders, Aasland, Amundsen, \& Grant, 1993; Allen, Litten, Fertig, \& Babor, 1997; Bush, Kivlahan, McDonell, Fihn, \& Bradley, 1998; Fiellin, Reid, \& O'Connor, 2000; Babor et al., 2001). While the total AUDIT score is used for risk diagnosis, the sub-scales can be meaningfully interpreted to identify hazardous drinking, harmful drinking, and alcohol dependence.

AUDIT scores range from 0 to 40 with a total score of 8 or more generally accepted as indicating hazardous and harmful alcohol use. In 2004, however, Neumann, Neuner, Gentilello, Weiss-Gerlach, Mentz, Rettig, ..., and Spies (2004) proposed that the cut-point of 8 was appropriate for men, but not adequate for women. They suggested that a cut-point of 5 is needed for women to allow the same level of sensitivity and specificity in identifying women at risk that 8 provides for men. Not surprisingly, this difference in cut-point is consistent with the lowered rate at which women metabolize alcohol relative to men and their developing higher blood alcohol levels than men when consuming the same amounts of alcohol (Baraona, Abittan, Dohmen, Moretti, Pozzato, Chayes, Schaefer, \& Lieber, 2001).

This study obtained an AUDIT scale range of 0.00-30.00 and a Cronbach's alpha reliability of $r=0.79$. The skewness statistic is 1.10 and the kurtosis statistic is 1.09 , which suggests that the distribution of scores approximates a normal distribution, with more respondents clustering towards the lower end and relatively few respondents scoring high on the AUDIT scale. 
Using list-wise deletion, the AUDIT mean score for the sample as a whole is $6.70(n=813$, SD $=5.57)$, hospitality business majors mean score is $7.81(n=241, \mathrm{SD}=5.78)$ and for other majors, it is $6.23(n=572$, $\mathrm{SD}=5.41)$. The sub-scale scores for hazardous alcohol use are $2.73(n=245, \mathrm{SD}=2.20)$ and $2.41(n=578$, $\mathrm{SD}=2.03)$, for harmful alcohol use $3.71(n=245, \mathrm{SD}=3.21)$ and $2.70(n=576, \mathrm{SD}=2.87)$, and for dependence symptoms $1.37(n=243$, SD = 1.56) and $1.15(n=573$, SD = 1.65), for hospitality business majors and other majors, respectively. Confidence intervals (95\%) were established and mean differences for AUDIT total and harmful alcohol use were significantly different.

Employed students scored 6.75 on AUDIT, while those not employed score AUDIT score of 6.59. This difference is not significantly different $(p>0.05)$. Students employed in hospitality businesses score 8.07 on AUDIT while those employed elsewhere obtained 6.17 on AUDIT. The sub-scale scores for hazardous alcohol use, dependence symptoms, and harmful alcohol use are 2.84 and 2.29, 1.50 and 1.17, and 3.72 and 2.75 for employees of hospitality businesses and those employed elsewhere, respectively. The independent samples $t$-tests found all of these differences to be significantly different $(p<0.05)$.

From the perspective of gender, men in the sample have an AUDIT score of 8.15 while women score 5.86. Male students that study hospitality business score 9.77 on AUDIT while women in hospitality business score 7.21. Among other majors, men score 7.73 while women score 5.13 on AUDIT total. The sub-sample differences are significant $(p=0.05$ ). Among the employed students, employees of hospitality businesses score 9.48 for men and 7.43 for women, while students employed elsewhere score 7.95 for men and 5.25 for women. Only the latter mean difference is statistically significant $(p=0.05)$.

Considering the recommended cut-points, about 53\% (52.7\%) of the hospitality business students have an AUDIT score in the 0-7 range and are classified as low-risk drinkers or non-drinkers, while $66.6 \%$ of other majors fall into that category. Using Neumann et al.'s (2004) recommended cut-points, $43.4 \%$ of the women in the total sample score above 5 and $38.4 \%$ of the men score above 8 on AUDIT. Fifty-five percent (54.6\%) of women who study hospitality score above 5 on AUDIT while $50.8 \%$ of men studying hospitality score above 8 . Among other majors, $47.4 \%$ of women score above 5 and $45.3 \%$ of men score above 8 on AUDIT. Among those employed in hospitality, 55.5\% of women score above 5 and $46.0 \%$ of men score above 8 on AUDIT, while among those employed elsewhere, 39.5\% of women score above 5 and $36.5 \%$ of men score above 8 on AUDIT. For greater detail regarding the AUDIT data, please see Borchgrevink et al. (2010).

SOC. Individuals' global orientation to life, their response to their inner and outer environments, is labeled their SOC (Antonovsky, 1987; 1993). This SOC is seen as a predictor of individual placement on the health-disease continuum of the salutogenic theory proposed by Antonovsky (1987; 1990; 1993). The SOC scale consists of 29 items on a 7-point semantic differential scale, with 11 items measuring comprehensibility, 10 items measuring manageability, and 8 items measuring meaningfulness. The higher an individual scores on the scale, the stronger the individual's SOC.

The SOC scale as published by Antonovsky (1987) was used. It has a potential range of 29-203. The obtained range is from 69 to 191, and with list-wise deletion, the mean SOC score is $138.64(n=857$; $\mathrm{SD}=20.97$ ). The skewness statistic is -0.41 and the kurtosis statistic is 0.34 , suggesting a normal distribution of SOC scores. Cronbach's alpha is $r=0.90$. The obtained range and mean scores are consistent with those in Eriksson and Lindström's (2005) meta-analysis. 
Considering the SOC from the perspective of majors, hospitality business students mean score is 138.99 $(n=262$, SD $=19.88)$ and other majors score is $138.48(n=595, \mathrm{SD}=21.44)$. Students that are employed in a hospitality business obtain an SOC score of $139.98(n=170$, SD $=21.20)$, while those employed elsewhere score $138.85(n=398, \mathrm{SD}=21.06)$. The men in the sample obtained a mean SOC score of $137.82(n=310$, SD $=21.40)$ which is lightly below the mean SOC score of $139.09(n=532$, SD $=20.87)$ obtained by the women. None of these mean score differences are statistically significant $(p>0.05)$.

\section{SOC and AUDIT}

Considering the relationship between SOC and AUDIT, a Pearson correlation using pair-wise deletion produces a negative association at $-0.20(n=857, p<0.01)$ for the sample as a whole. The Pearson correlation coefficients for the male and female sub-samples are $-0.22(n=285, p<0.01)$ and $-0.19(n=478, p<0.01)$, while the correlation coefficients for hospitality majors and other majors are $-0.16(n=231, p<0.01)$ and -0.23 ( $n=544, p<0.01)$, respectively.

Antonovsky (1993) argued that the SOC sub-scales should not be considered individually and Babor et al. (2001) suggested that the AUDIT sub-scales could be interpreted as distinct constructs. Table 1 below contains the matrix of correlation coefficients obtained between the SOC and the AUDIT sub-scales of hazardous alcohol use, dependence symptoms, and harmful alcohol use. While the relationship between the SOC and each of the AUDIT sub-scales is statistically significant $(p<0.01)$, it is the association between the SOC and dependence symptoms that is the strongest with $r=-0.28$.

Table 1

Correlation Matrix SOC and AUDIT Sub-scales

\begin{tabular}{|c|c|c|c|c|c|}
\hline & & SOC total & $\begin{array}{l}\text { AUDIT } \\
\text { Hazardous alcohol } \\
\text { use }\end{array}$ & $\begin{array}{l}\text { AUDIT } \\
\text { Dependence } \\
\text { symptoms } \\
\end{array}$ & $\begin{array}{l}\text { AUDIT } \\
\text { Harmful alcohol } \\
\text { use } \\
\end{array}$ \\
\hline \multirow{3}{*}{ SOC total } & Pearson correlation & 1 & $-0.106^{* *}$ & $-0.276^{* *}$ & $-0.162^{* *}$ \\
\hline & Sig. (1-tailed) & & 0.001 & 0.000 & 0.000 \\
\hline & $N$ & 857 & 783 & 778 & 781 \\
\hline \multirow{3}{*}{$\begin{array}{l}\text { AUDIT: } \\
\text { Hazardous alcohol use }\end{array}$} & Pearson correlation & $-0.106^{* *}$ & 1 & $0.469^{* *}$ & $0.487^{* *}$ \\
\hline & Sig. (1-tailed) & 0.001 & & 0.000 & 0.000 \\
\hline & $N$ & 783 & 823 & 815 & 820 \\
\hline \multirow{3}{*}{$\begin{array}{l}\text { AUDIT: } \\
\text { Dependence symptoms }\end{array}$} & Pearson correlation & $-0.276^{* *}$ & $0.469^{* *}$ & 1 & $0.591^{* *}$ \\
\hline & Sig. (1-tailed) & 0.000 & 0.000 & & 0.000 \\
\hline & $N$ & 778 & 815 & 816 & 814 \\
\hline \multirow{3}{*}{$\begin{array}{l}\text { AUDIT: } \\
\text { Harmful alcohol use }\end{array}$} & Pearson correlation & $-0.162^{* *}$ & $0.487^{* *}$ & $0.591^{* *}$ & 1 \\
\hline & Sig. (1-tailed) & 0.000 & 0.000 & 0.000 & \\
\hline & $N$ & 781 & 820 & 814 & 821 \\
\hline
\end{tabular}

Note. ${ }^{* * *}$ : Correlation is significant at the 0.01 level (1-tailed).

\section{Discussion}

The AUDIT data suggest that there is some truth to the claim that hospitality students and hospitality employees consume alcohol at higher levels than other groups of students and employees. It is also found that men consume alcohol at higher levels than women across both the student and the employment sub-sample. Furthermore, considering the AUDIT consumption data from the perspective of the recommended cut-points for men and women, larger proportions of men and women studying in hospitality and working in hospitality are at risk of developing alcohol-related problems than the proportion of men and women at risk in other majors and other occupations. 
The attempt to explain this finding from the perspective of the self-selection hypothesis using Antonovsky's $(1987 ; 1993)$ salutogenic theory and the SOC scale as explanatory vehicle failed. The SOC scores and ranges obtained are consistent with those reported by Eriksson and Lindström (2005) in their meta-analysis. None of the sub-sample SOC scores, however, differ significantly $(p>0.05)$ and the SOC cannot, according to the data, be used to explain the reason why individuals who study or work in hospitality consume more alcohol than those that study and work elsewhere. One of the reasons for this null-finding can be that the individual SOC scores had yet to stabilize in this young-adult population. Antonovsky (1987) suggested that the SOC will fluctuate till the end of young adulthood or till approximately 30 years of age.

While the data suggest that the SOC cannot be used as the basis for explaining student self-selection into hospitality studies or hospitality work, the results do suggest that the SOC can be used as a predictor of alcohol consumption. This can be important from a health perspective. Correlation analysis established that the SOC correlates to alcohol consumption and the assessment of alcohol-related risky behaviors as measured by AUDIT. The negative association suggests that as SOC increases, alcohol consumption decreases with the strongest negative association found between alcohol dependence symptoms and SOC. The SOC does appear to have a salutogenic effect. The negative association was stronger for the men compared to the women in the sample. This can possibly be explained by the lower alcohol tolerance and thus lower alcohol consumption among women. It is puzzling, however, that the negative association is weaker among the hospitality students than among students in other majors.

The associations found between the SOC and the AUDIT sub-scales are important. They suggest that the SOC may be used to predict risky alcohol consumption in college-age populations not previously diagnosed as having problems related to alcohol consumption. The strongest correlation is found between the SOC and the AUDIT sub-scale for alcohol dependence symptoms. Compared to the two other AUDIT sub-scales, the dependence symptoms sub-scale is the sub-scale that most clearly taps an existing health-related condition. The sub-scales of hazardous alcohol use and harmful alcohol use tap behaviors that are antecedents to negative health effects. In sum, the SOC-AUDIT associations reported herein further strengthen the salutogenic nature of the SOC.

Given the SOC-AUDIT associations, the SOC may also become useful for monitoring and identifying potential at risk populations. All businesses, including hospitality businesses, should be concerned with the health of their employees, so as to keep them healthy and thus productively engaged but also to minimize employee related health and insurance costs. Furthermore, service quality, productivity, and profits may suffer as a consequence of alcohol consumption among hospitality business employees (Larsen, 1994; Frone, 2013), adding to the potential importance and usefulness of predicting and monitoring the risk of engagement in risky alcohol consumption behaviors.

While the association between the SOC and the AUDIT sub-scales is important, the test of the self-selection hypothesis using Antonovsky's $(1987 ; 1990)$ salutogenic approach is also important in that null-findings are also explanatory. Additional research is needed to understand the increased proclivity for alcohol consumption among hospitality populations compared to other relevant populations. 


\section{References}

Allen, J. P., Litten, R. Z., Fertig, J. B., \& Babor, T. (1997). A review of research on the alcohol use disorders identification test (AUDIT). Alcoholism: Clinical and Experimental Research, 21(4), 613-619.

Antonovsky, A. (1979). Health, stress and coping. San Francisco: Jossey-Bass Publishers.

Antonovsky, A. (1987). Unraveling the mystery of health: How people manage stress and stay well. San Francisco: Jossey-Bass Publishers.

Antonovsky, A. (1990). Studying health vs. studying disease. In Congress for Clinical Psychology and Psychotherapy, Berlin. Retrieved from http://www.ensp.unl.pt/saboga/soc/pulic/soc_AAconference_berlim_91.pdf

Antonovsky, A. (1993). The structure and properties of the sense of coherence scale. Social Science \& Medicine, 36(6), 725-733.

Babor, T. F., Higgins-Biddle, J. C., Saunders, J. B., \& Monteiro, M. G. (2001). AUDIT The alcohol use disorders identification test. Guidelines for use in primary care (2nd ed.). Geneva, Switzerland: World Health Organization. Department of Mental Health and Substance Dependence.

Baraona, E., Abittan, C. S., Dohmen, K., Moretti, M., Pozzato, G., Chayes, Z. W., Schaefer, C., \& Lieber, C. S. (2001). Gender differences in pharmacokinetics of alcohol. Alcoholism: Clinical and Experimental Research, 25(4), 502-507.

Borchgrevink, C. P., \& Borchgrevink, H. C. (2013). Self-selection and alcohol consumption. International Journal of Hospitality Management, 33(1), 389-396.

Borchgrevink, C. P., Sciarini, M. P., \& Borchgrevink, H. C. (2010). Alcohol consumption among hospitality students and hospitality employees: A replication and pilot study. Proceedings of the 2010 Annual International Council on Hotel, Restaurant \& Institutional Education Conference.

Bush, K., Kivlahan, D. R., McDonell, M. B., Fihn, S. D., \& Bradley, K. A. (1998). The AUDIT alcohol consumption questions (AUDIT-C): An effective brief screening test for problem drinking. Archives of Internal Medicine, 158(16), 1789-1795.

Cohen, J. (1988). Statistical power analysis for the behavioral sciences (2nd ed.). Hillsdale, NJ: Lawrence Erlbaum Associates, Publishers.

Corsun, D. L., \& Young, C. A. (1998). An occupational hazard: Alcohol consumption among hospitality managers. Marriage \& Family Review, 28(1/2), 187-211.

Eriksson, M., \& Lindström, B. (2005). Validity of Antonovsky's sense of coherence scale: A systematic review. Journal of Epidemiology \& Community Health, 59(6), 460-466.

Eriksson, M., \& Lindström, B. (2006). Antonovsky's sense of coherence scale and the relation with health: A systematic review. Journal of Epidemiology \& Community Health, 60(5), 376-381.

Fiellin, D. A., Reid, M. C., \& O’Connor, P. G. (2000). Screening for alcohol problems in primary care: A systematic review. Archives of Internal Medicine, 160(13), 1977-1989.

Fleming, M. F., Barry, K. L., \& MacDonald, R. (1991). The alcohol use disorders identification test (AUDIT) in a college sample. The International Journal of the Addictions, 26(11), 1173-1185.

Frone, M. R. (2013). Alcohol and illicit drug use in the workforce and workplace. Washington, DC: American Psychological Association.

Geyer, S. (1997). Some conceptual considerations on the sense of coherence. Social Science \& Medicine, 44(12), 1771-1779.

Homish, G. G., \& Leonard, K. E. (2008). The social network and alcohol use. Journal of Studies on Alcohol and Drugs, 69(6), 906-914.

Kjærheim, K., Mykletun, R., \& Haldorsen, T. (1996). Selection into the restaurant business based on personality characteristics and the risk of heavy drinking. Personality and Individual Differences, 21(4), 625-629.

Kjærheim, K., Mykletun, R., Aasland, O. G., Haldorsen, T., \& Andersen, A. (1995). Heavy drinking in the restaurant business: The role of social modeling and structural factors of the work-place. Addiction, 90(11), 1487-1495.

Klineberg, O. (1954). Social psychology. New York, NY: H. Holt \& Company.

Kouvonen, A., \& Lintonen, T. (2002). Adolescent part-time work and heavy drinking in Finland. Addiction, 97(3), 311-318.

Larsen, S. (1994). Alcohol use in the service industry. Addiction, 89(6), 733-741.

Larsen, S., \& Jørgensen, H. (2003). Better than their reputation? - Do hotel and restaurant students drink more? Food Service Technology, 3(3-4), 151-155.

Midanik, L. T., Soghikian, K., Ransom, L. J., \& Polen, M. R. (1992). Alcohol problems and sense of coherence among older adults. Social Science \& Medicine, 34(1), 43-48. 
Neumann, T., Neuner, B., Gentilello, L. M., Weiss-Gerlach, E., Mentz, H., Rettig, J. S., ..., \& Spies, C. D. (2004). Gender differences in the performance of a computerized version of the alcohol use disorders identification test in subcritically injured patients who are admitted to the emergency department. Alcoholism: Clinical and Experimental Research, 28(11), 1693-1701.

Neuner, B., Miller, P., Maulhardt, A., Weiss-Gerlach, A., Neumann, T., Lau, A., ..., \& Spies, C. (2006). Hazardous alcohol consumption and sense of coherence in emergency department patients with minor trauma. Drug and Alcohol Dependence, 82(2), 143-150.

Newcomb, T. M. (1958). Attitude development as a function of reference groups: The Bennington study. In E. E. Maccoby, T. M. Newcomb, \& E. L. Hartley (Eds.), Readings in social psychology. New York, NY: H. Holt \& Company.

O’Hara, R., Harker, D., Raciti, M., \& Harker, M. (2007). Risky alcohol consumption by young, female Australians: The influence of significant others. Social Marketing Quality, 13(4), 26-46.

Pizam, A. (2010). Alcoholism among hospitality employees. International Journal of Hospitality Management, 29(4), 547-548.

Plant, M. A. (1979). Drinking careers: Occupations, drinking habits and drinking problems. London, England: Tavistock Publications Limited.

Poppius, E., Virkkunen, H., Hakama, M., \& Tenkanen, L. (2008). The sense of coherence and risk of injuries: Role of alcohol consumption and occupation. Journal of Epidemiology \& Community Health, 62(1), 35-41.

Robinson, E., Tobias, T., Shaw, L., Freeman, E., \& Higgs, S. (2011). Social matching of food intake and the need for social acceptance. Appetite, 56(3), 747-752.

Saunders, J. B., Aasland, O. G., Amundsen, A., \& Grant, M. (1993). Alcohol consumption and related problems among primary health care patients: WHO collaborative project on early detection of persons with harmful alcohol consumption - I. Addiction, 88(3), 349-362.

Skog, O. (1985). The collectivity of drinking cultures: A theory of the distribution of alcohol consumption. British Journal of Addiction, 80(1), 83-99.

Whitehead, P. C., \& Simpkins, J. (1983). Occupational factors in alcoholism. In B. Kissin, \& H. Begleiter (Eds.), The pathogenesis of alcoholism. New York, NY: Plenum Press.

Zhu, J. F., Tews, M. J., Stafford, K., \& George, R. T. (2011). Alcohol and illicit substance use in the food service industry: Assessing self-selection and job-related risk factors. Journal of Hospitality \& Tourism Research, 35(1), 45-63. 